\title{
Juana de Ibarbourou, Alfonso Reyes y la literatura mexicana en 1929. Amistad literaria y políticas del espíritu
}

\section{Juana de Ibarbourou, Alfonso Reyes and Mexican Literature in 1929. Literary Friendship and Politics of the Spirit}

\section{Mariana Moraes Medina*}

Resumen: este artículo examina la relación de Juana de lbarbourou con Alfonso Reyes y la literatura mexicana durante 1929, a partir de la reconstrucción de los intercambios y encuentros que tuvieron lugar entre los escritores durante ese año, en particular, los eventos relacionados con la organización del homenaje a Amado Nervo en Montevideo —en su décimo aniversario luctuoso - y la ceremonia que elevó a la poeta a "Juana de América". El objetivo del trabajo es analizar, a través de los aportes de la sociología de la literatura, las afinidades, dinámicas de patrocinio literario y transferencia de prestigio entre los autores, y su relación con los proyectos de nación y de cultura promovidos por México y Uruguay a finales de la década de los veinte. Los intercambios iniciales entre Reyes e lbarbourou (espejo de las lógicas modernistas de promoción y patrocinio patriarcal) colaboraron con la consagración y construcción de la imagen continental de la escritora en 1929 y le aseguraron una aliada de gran notoriedad a la diplomacia cultural del México posrevolucionario en el Río de la Plata.

Palabras Clave: Juana de Ibarbourou; Alfonso Reyes; México; Uruguay; Amado Nervo; Sor Juana Inés de la Cruz.

ABSTRACT: This article examines the Uruguayan poet Juana de Ibarbourou's relationship with Alfonso Reyes by reconstructing the exchanges and meetings that took place between them in 1929, in particular the events related to the organization of a tribute to Amado Nervo in Montevideo on the tenth anniversary of his death and the ceremony that elevated Ibarbourou to "Juana de América". It does so by analyzing contributions from the sociology of literature, affinities, dynamics of literary sponsorship and transfer of prestige among the authors, and their relationships with their nations and the culture projects promoted in Mexico and Uruguay in the late twenties. The initial exchanges between Reyes and Ibarbourou (a reflection on the modernist logics of patriarchal promotion and sponsorship) helped initiate and construct this writer's continental image in 1929 and secured an important ally to the cultural diplomacy of post-revolutionary Mexico in the La Plata River region.

Key woRDS: Juana de Ibarbourou; Alfonso Reyes; México; Uruguay; Amado Nervo; Sor Juana Inés de la Cruz.

Recibido: 1 de marzo de 2019

Aceptado: 9 de agosto de 2019

* El presente trabajo es resultado de la estancia de investigación como becaria del Programa de Becas Posdoctorales de la UNAM, realizada en el Centro de Investigaciones sobre América Latina y el Caribe, con la asesoría de la doctora Regina Crespo Franzoni (2018-2019). Universidad Adolfo Ibánez. Conicyt (Chile); sNI-ANII (Uruguay) (mmoraes.medina@gmail.com). 


\section{INTRODUCCIÓN}

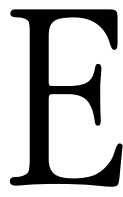

1 Uruguay que defraudó a José Vasconcelos en su estadía de 1922 por encontrarse demasiado concentrado en Europa y en sí mismo fue mostrando, avanzada la década, una franca apertura a la idea de integración latinoamericana. Periódicos y revistas de la época guardan el interés uruguayo por los procesos políticos y sociales de los países hermanos y el registro de las polémicas en torno a la identidad y la construcción de un canon cultural propio - nacional y americano-. Aunque hubo obras como las de Sabat Ercasty y Pereda Valdés, la filosofía de Carlos Vaz Ferreira, el espíritu de publicaciones como Ariel, La Cruz del Sur y La Pluma y el impulso del movimiento reformista universitario, que ayudaron a construir la proyección americana de la nación, ninguna de estas figuras ni proyectos intelectuales alineados a una conciencia y una estética latinoamericanas tuvo tanto éxito como la fragua de una poeta continental, nos referimos a la transformación de Juana de Ibarbourou (1892-1979) en "Juana de América". Su centralidad en el canon uruguayo del veinte parecía ya asegurada desde la publicación de Las lenguas de diamante (1919) y quedó incluso sugerida en el testimonio del ya referido viaje de Vasconcelos, quien comentaba: "No se puede mencionar el Uruguay sin que venga a la mente la imagen de Juana de Ibarbourou" (Vasconcelos 1925: 143).

Juana había venido a reforzar la presencia de las mujeres en el campo cultural uruguayo, un aspecto que desde Delmira Agustini y María Eugenia Vaz Ferreira, las poetas del 900, llamaba la atención en el conjunto de naciones latinoamericanas y señalaba a Montevideo como una cuna de libertades. ${ }^{1}$ El mito sirvió para fortalecer la idea de una expresión propiamente americana (y fuertemente asociada a la poesía femenina). Por otra parte,

1 En 1933, el escritor Salvador Novo visitó Montevideo como miembro de la Legación mexicana que asistía a la Conferencia Panamericana y manifestó su sorpresa por el dinamismo de las escritoras uruguayas. "Se diría que las mujeres [...] se han encargado con fervor de sostener y continuar una cultura nacional, que ya cuenta con el pasado de María Eugenia Vaz Ferreira, de preclaro apellido, y con Delmira Agustini, y en el presente con Juana, con Luisa Luisi" (Novo 1996: 761). 
la escritora encarnó la imagen que el país buscaba proyectar en el exterior -desde el optimismo de su cercano Centenario-: una alianza de cultura, juventud y modernidad.

Si bien la poesía de Ibarbourou, su inserción en el sistema literario uruguayo y su vínculo con el poder oficial han concitado largamente la atención de la crítica, no ha ocurrido lo mismo con la integración y contacto de la autora con redes intelectuales transnacionales y la incidencia de éstas en la circulación de su obra. En particular, poco se ha avanzado sobre las condiciones y el impacto del primer tramo de su relación con Alfonso Reyes (1889-1959), un intercambio cuyo estudio podría redundar en una ampliación de las perspectivas manejadas hasta el momento acerca de la consagración de la poeta en 1929 y de la labor de la diplomacia mexicana de las letras en el campo cultural uruguayo. Atendiendo a esto, el objetivo de este artículo es abordar la amistad e intercambios entre los autores desde la lente de la sociología de la literatura (Sapiro 2016), en procura de clarificar el espacio de posiciones del momento en el campo cultural nacional y extranjero, y las propias tomas de posición de los autores, así como lo modos de acumulación y donación de capital simbólico (Bourdieu 1995) que llevaron adelante.

\section{MÉXICO EN URUGUAY: LA DIPLOMACIA DE LAS LETRAS}

Antes de abordar el estudio de la relación entre Ibarbourou y Reyes, resulta pertinente delinear un mínimo contexto sobre los vínculos culturales entre México y Uruguay por esos años. Para ello resulta imprescindible repasar la recepción de la Revolución mexicana en el país austral. Desde el estallido de la misma, aunque con intermitencias, los uruguayos mostraron un gran interés por seguir de cerca la evolución del proceso revolucionario. El historiador Carlos Rama (1957) ha indicado tres etapas en la recepción de la Revolución en Uruguay: 1) la inmediata a 1910, concentrada en los sectores anarquistas y socialistas; 2) la que inicia la invasión estadounidense a Veracruz (1914) y que se caracterizó por el incremento 
del interés en todos los sectores sociales, pero especialmente entre los estudiantes universitarios, y 3) durante los últimos años de la década de 1920, en los que se comprueba un nuevo interés por la política y la cultura de México por parte de la intelectualidad uruguaya.

Entre la segunda y la tercera etapa, viajeros intelectuales, agregados obreros y estudiantiles y diplomáticos mexicanos fueron los principales agentes de contacto. El empleo de destacados escritores en las representaciones mexicanas con tareas de promoción cultural fue uno de los logros más resonantes de la política exterior ideada por Isidro Fabela. En Uruguay, esa "diplomacia de las letras" de México se desarrolló (con cargos consulares o en comisiones pasajeras) a través de figuras como el propio Fabela, Nervo, Vasconcelos, González Martínez y Reyes. Un botón de muestra del triunfo de la política exterior posrevolucionaria, cuyo impacto en el Río de la Plata estudió en profundidad Pablo Yankelevich (1997), se refleja en el siguiente pasaje de un discurso de la uruguaya Luisa Luisi:

Hemos aprendido a conocer y amar a la nación hermana, a través de sus más grandes literatos, convertidos por la sabia diplomacia mexicana, en los más puros heraldos de su cultura nacional. Así amamos y lloramos con hondo dolor de poetas y de hermanos al dulce Amado Nervo, que en su cristiana generosidad, nos lo dio todo, su corazón de Asís, y el mismo soplo vital de su existencia. Así aprendimos a conocer y a amar al noble poeta González Martínez, de tan alta espiritualidad en su poesía como noble dignidad en su arte; amigo grande a quien recuerdo hoy emocionada en esta fiesta que el Uruguay dedica a México. Y así también Alfonso Reyes, investido por un Gobierno transitorio de una transitoria Representación Diplomática, inviste, hoy y siempre para nosotros, la representación ilimitada de la cultura de su pueblo (Luisi 1928: 20).

En el marco de este acercamiento, 1928 debe considerarse como el tramo de mayor entusiasmo en la recepción de lo mexicano en Uruguay, coincidiendo con la fundación del Comité Uruguay-México, un organismo de solidaridad con la coyuntura mexicana, fundado por un conjunto de más de cuarenta personalidades del campo intelectual uruguayo y que tuvo a la cabeza a la ya mencionada poeta, crítica literaria y pedagoga Luisa Luisi (1883-1940). 
La primera actividad pública del grupo consistió en la organización de un homenaje a México, motivo por el cual Luisi extendió una invitación a Alfonso Reyes, en su primer periodo como Embajador de México en Argentina (1927-1930), para que realizara una visita oficial a Uruguay. Este acto -que inauguraría las actividades del Comité y que contó con una enorme afluencia de público - fue el inicio de una "ola de difusión de los valores mexicanos" que se extendería hasta 1929 y que reforzaría la presencia de Reyes en la orilla oriental por esos años. ${ }^{2}$

Cuando el autor de la Visión de Anábuac llegó a Montevideo, el país se encontraba aún bajo la hegemonía ideológica del batllismo, tronco fundante del relato del Uruguay moderno (una república civilizada y a la vanguardia en términos de derechos). Fue recibido por una intelectualidad afín a los proyectos de signo progresista y reformista, que manifestaba un gran interés por la obra educativa y social de la Revolución y una fuerte implicación con la defensa de la soberanía mexicana ante los embates del imperialismo estadounidense. ${ }^{3}$

En lo que tocaba a Reyes, hay que apuntar que su misión diplomática en el Río de la Plata no era sencilla; debía representar al México del presidente Calles, un gobierno sacudido por la guerra cristera, el asesinato de Obregón y el ataque de la prensa que representaba los intereses estadounidenses y de la Iglesia católica (Garciadiego 2015: 235). Parejo con esto, en el campo cultural nacional tenía lugar un intenso debate en torno a la construcción del México posrevolucionario. Por este motivo la mexicanidad estuvo en el centro de las polémicas artísticas y alimentó, a grandes rasgos, dos posturas: una cercana al poder oficial, atravesada por notas populistas y nacionalistas, y por otra parte, la que defendía una con-

2 Véase carta inédita de Luisi a Alfonso Reyes: Archivo Particular de Alfonso Reyes, 28 de marzo de 1928. El epistolario inédito entre Alfonso Reyes y Luisa Luisi constituyó una valiosa fuente para esta investigación. Agradecemos al doctor Javier Garciadiego y a Eduardo Mejía el acceso a estos y otros materiales conservados en el Archivo Alfonso Reyes (INBA-Capilla Alfonsina).

3 La propia fundación del Comité Uruguay-México debe considerarse una declaración política de apoyo "a la gran obra de construcción democrática que se gesta, dolorosa y acaso turbiamente en este gran país hermano". Véase "El Comité Uruguay-México hace conocer su programa de acción", El País (10 de mayo de 1928: 3). 
figuración identitaria universalista y cosmopolita. Reyes, quien fuera educado en el seno de la élite porfirista y perdiera a su padre en uno de los enfrentamientos de la Decena Trágica -mientras este luchaba por la causa reaccionaria-, no tuvo demasiada afinidad con la primera, entre otras cosas porque nunca pudo apropiarse completamente del México revolucionario ni de los valores sociales derivados del proceso. En ese sentido se comprende su defensa del servicio exterior de la república como una representación apolítica. Afirmaba Reyes: "La propaganda cultural y espiritual de México (nunca la intromisión en la política interna ni la inoportuna prédica sectaria) que hoy se exige de nuestra representación diplomática le dará a ésta un sitio único, que se hará sentir en el mundo como un valor positivo" (Reyes 2001: 143). Con todo, el escritor en funciones del servicio exterior mexicano no podía desaprovechar ninguna oportunidad que se le presentara para contrarrestar la imagen de país inestable y gobernado por la violencia. Por este motivo apoyó de diversas maneras las actividades del Comité Uruguay-México, como se sigue de la correspondencia que mantuvo con Luisi. ${ }^{4} \mathrm{La}$ amistad entre los autores pronto mostró sus limitaciones, básicamente debido al sentido excesivamente utilitario que los dos imprimieron a su relación: el diplomático, procurando los beneficios de las eficaces labores de la "buena" propaganda de México que promovía la autora, y ésta, la dádiva de una legitimación mediada por el escritor consagrado en América Latina y Europa que era Reyes. ${ }^{5}$

De otro calado, aunque atravesada igualmente por las ansiedades de la representación de la cultura nacional y de las dinámicas de reconocimiento y promoción propias del campo literario, fue la amistad que

4 El Comité organizó conferencias como las dictadas por Emilio Frugoni, escritor y líder del Partido Socialista Uruguayo, en el Paraninfo de la Universidad (publicadas luego bajo el título de La lección de México, 1928), en las que se destacaban los logros en justicia social del proceso posrevolucionario, en particular la dignificación del indio y diversos aspectos de la Constitución de 1917. También hubo eventos orientados a temas o autores del campo literario mexicano como el homenaje al poeta Salvador Díaz Mirón con motivo de su deceso, o las conferencias de Luisi sobre sor Juana Inés de la Cruz, o de Sábat Ercasty sobre Gutiérrez Nájera.

5 Para más detalle sobre esta relación y el funcionamiento del Comité Uruguay-México, véase Moraes 2019. 
entablaron Reyes y Juana de Ibarbourou, quienes se conocieron el 28 de mayo de 1928, precisamente durante la primera estadía del mexicano en Montevideo. Previo a las actividades oficiales que lo ocuparían intensamente en la capital uruguaya, tuvo lugar el encuentro con la poeta, según registró el autor en su diario: "Visita a Juana de Ibarbourou que tiene muy enfermo al hijo y la casa en obra. Tristeza" (Reyes 2010: 54). La sucesión de cartas entre los escritores escenifica un rápido incremento de la confianza y la construcción de una relación personalísima, que combinó las confidencias con la construcción de afinidades e intercambios propios del quehacer intelectual. La dedicación de Ibarbourou a la organización de un homenaje a Nervo en Montevideo, en mayo de 1929, y la presencia de Reyes, meses después, en el acto que consagró a la poeta como "Juana de América" constituyen dos instancias de gran riqueza simbólica y de notable utilidad para el estudio de la naturaleza de los intercambios entre los escritores y sus implicancias.

La hipótesis de lectura que proponemos en este trabajo consiste en que la amistad literaria entre Ibarbourou y Reyes también obró a favor de la "apoteosis" de la escritora en el campo literario nacional y extranjero. Si bien tanto Reyes como Ibarbourou eran escritores reconocidos al momento de iniciar su relación, interesa profundizar la instrumentalización que realizaron de la sociabilidad intelectual, las apropiaciones culturales y literarias y cómo éstas sirvieron no sólo a sus propias trayectorias intelectuales (y política, en el caso del mexicano) sino al modelo de cultura y nación que representaban.

REYES E IBARBOUROU:

DEBILIDAD Y PATROCINIO LITERARIO

De las fuentes disponibles para el estudio del vínculo entre los escritores en cuestión, la más rica -junto con el Diario de Reyes- es el epistolario de los autores, que se extiende entre 1928 y 1959, año de la muerte del mexicano. Debemos a Serge I. Zaïtzeff (2001) la labor de edición de estas 
cartas y el primer y muy documentado acercamiento crítico a la relación de los escritores. Quedan, sin embargo, por ensayar otros ángulos de lectura.

Para empezar, diremos que es muy llamativa no sólo la continua autorrepresentación que propone Ibarbourou de sí misma como víctima de males ("si no estuviera dolorosamente convencida de que la enemistad de los hados", [Reyes e Ibarbourou 2001: 27]), sino también la naturalidad con la que, desde las primeras cartas, le confiesa a Reyes (un escritor renombrado e influyente) toda su debilidad. Detalles de la vida doméstica, las enfermedades de su marido y de su hijo, que la condenan al encierro y a la angustia; los problemas económicos sugieren la idea de la vida como una acumulación de males físicos y espirituales, ${ }^{6}$ lo que contrasta con la imagen "oficial" que se pretendió dar de la poeta-ícono cultural como un dechado de estabilidad y felicidad familiar. ${ }^{7}$ Entre fines de 1928 y principios de 1929, alude, con insistencia, a la locura: "Creo que todos estamos medio locos en esta casa" (2001: 24); "Voy a parecerle loca" (2001: 28), entre otros detalles que aluden a cierto desequilibrio nervioso. Asimismo, recrea para Reyes una atmósfera marcada por lo irracional a través de anécdotas como la de su participación en una sesión de espiritismo, su miedo ante una "presencia invisible" en su casa en la madrugada, la

6 Escribe Juana: "Siempre he estado rodeada de penas. Murieron mis dos hermanos, mis padres siempre se llevaron muy mal, mamá pasó años y años enferma; como si la expiación de esa alma mala empezara desde entonces, mi juventud, mi soltería brevísima, estuvieron cargadas de angustia. luego la enfermedad de mi marido desde hace 7 años, el nene muy delicado de pequeño, su gran difteria y parálisis de ahora, quebrantos de fortuna, la casa que vuelve a caérsenos casi ahora, la muerte de ese perrito que era para nosotros un niño, y mamá, en este momento, con una erisipela que la hace gritar de dolor noche y día. Y no sé si Ud. se da cuenta, Reyes, que esto es toda una vida pasada así" (Reyes e Ibarbourou 2001: 29).

Una aproximación in extenso al manejo de Ibarbourou del género epistolar arroja datos interesantes. En vista de ello, la debilidad y acumulación de males que exhibe ante Reyes podrían ser leídas como parte de una estrategia que la autora (deseosa de escapar de las marcas de origen - ausencia de linaje, pertenencia a una clase media provinciana-) habría forjado a lo largo de su vida para obtener favores de personas con poder. Según ha señalado Inés de Torres, la autora de Raíz salvaje desarrolló una gran habilidad en la escritura de este tipo de misivas: "en lo privado, Juana será una incansable escritora de cartas a políticos de distintos partidos, pidiendo o reclamando favores o beneficios para ella, su familia o sus amigos" (Torres 2017: 57). 
creencia en estar poseída por un espíritu maligno o sus continuos malos presentimientos. Estas y otras vivencias abonan la imagen de una mujer en contacto con presencias invisibles, supersticiosa y al mismo tiempo dueña de un profundo misticismo derivado de su fe cristiana.

Raúl Ianes (2010) ha propuesto una lectura de estos episodios de enajenación o fragilidad mental como un trasunto de la sensibilidad creadora, de la experiencia estético-literaria. Para el crítico, la construcción testimonial de Juana es deudora de una sensibilidad de época, puntualmente, de la sensibilidad instalada por el modernismo hispanoamericano, en su decadentismo y gusto por lo paranormal. Desde nuestro punto de vista, la recurrencia de la escritora a autoimágenes de fragilidad y patetismo, es decir, la elección de construirse desde la debilidad, debería ser leída como una estrategia de dominio en el sentido de lo que ha señalado Carina Blixen para las poetas uruguayas del novecientos: "Muchas veces las mujeres ejercieron un poder real, oculto tras las formalidades del dominio que se ejercita hacia fuera: la locura, la histeria, las dolencias pudieron ser vehículo para ejercitar un control tortuoso, del que se es victimario y víctima a un tiempo" (Blixen: 2014). Esta estrategia, que podría vincularse con la idea de "las tretas del débil" propuesta por Josefina Ludmer (1984), aparece combinada con otras más directas y que hacen a la captación del afecto y la benevolencia de su interlocutor. Así, Juana dice haber encontrado en Reyes "el alma amiga capaz de recoger con piedad, comprensión y paciencia estas confidencias que nunca dejaría caer en otro oído" (Reyes e Ibarbourou 2001: 28) y no cesa de manifestarle cuánto lo necesita: "Hay días, Alfonso, que pesan sobre el hombro como un muerto. Entonces, ya lo ves, doy un salto sobre el río para encontrarte. Dime algo, no me dejes ya siempre tan sola" (2001: 36).

Las respuestas de Reyes a los males de su amiga lo retratan implicado en su salud física y espiritual, y asume, con cierto paternalismo, la función de darle consuelo y seguridad a su corresponsal. Por momentos, el escritor ensaya una suerte de asistencia como terapeuta freudiano: "todo exorcismo es una palabra. En cuanto descubrimos el nombre de nuestro mal, en cuanto empezamos a expresarlo, el mal se disipa [...] Ahora que 
Ud. está en tratamiento conmigo, haga una prueba" (Reyes e Ibarbourou 2001: 31- 33). Tanto Zaïtzeff (2001: 14) como Castañón (2010: XXIII) han destacado la dedicación y generosidad mostradas por Reyes en el vínculo epistolar con amistades femeninas. Sin desestimar del todo estos juicios habría que preguntarse igualmente hasta dónde ese comportamiento no era funcional a un modo de sociabilidad, notoriamente galante, desarrollado por los escritores varones hacia sus pares mujeres (y habilitado en cierta medida por ellas, al autorrepresentarse desde la debilidad o la falta). En el caso de Reyes e Ibarbourou se advierte en este "juego" el sello de una práctica de legitimación patriarcal muy común en el modernismo, como ha estudiado José María Martínez (2015), y a través de la cual los escritores varones "autorizaban" a sus pares femeninos. Delmira Agustini con Rubén Darío; Gabriela Mistral con Amado Nervo o Juana de Ibarbourou con Unamuno, Ugarte y Santos Chocano, son algunos casos que ejemplifican el establecimiento de una relación "efébica" entre los artistas varones y sus discípulas mujeres. El paso de Reyes por Sudamérica tendría mucho de esta dinámica de patrocinio literario, si se atiende a cómo ayudó a promover las obras de sus amigas Meireles, Mistral, Ocampo, Luisi e Ibarbourou, entre otras. En lo que hace a las uruguayas, el escritor les ofreció colaborar con la revista Contemporáneos, obteniendo por parte de Luisi un ensayo sobre sor Juana Inés de la Cruz y de Juana unos poemas inéditos. Asimismo, ayudó a la edición de una antología de poemas de Ibarbourou en Madrid, en 1930, dedicó una reseña al libro La rosa de los vientos en la revista Sur (Reyes 1931), entre otras formas de reconocimiento y apoyo a sus iniciativas, como se verá en lo que sigue.

\section{LA "HORA DE FERVOROSA RECORDACIÓN" DE NERVO EN MONTEVIDEO}

A su llegada a Montevideo en 1922, José Vasconcelos reseñó un itinerario de recorridos, comidas y visitas oficiales que incluyeron escuelas y otras instituciones. Al pasar por la Universidad de la República, el escritor apun- 
tó que "flotaba todavía la memoria de Amado Nervo" (Vasconcelos 1925: 146). En efecto, en los años veinte, el poeta de Nayarit era aún la figura más importante de la cultura mexicana en el imaginario uruguayo. Este arraigo en la memoria de los orientales se debía principalmente a que su deceso, en mayo de 1919, tuvo lugar en Montevideo, capital a la que había llegado como ministro plenipotenciario de México, bajo el gobierno de Carranza. Los honores fúnebres tributados al poeta y diplomático cobraron dimensiones insólitas tanto en Uruguay como en el continente. ${ }^{8}$ No hubo muestra más grande de duelo y solidaridad en la historia de Latinoamérica y el México posrevolucionario obtuvo con ello un verdadero hito en su proyección en el exterior (Gros Espiell 1990; Amado Nervo 1995).

El 24 de mayo de 1929 se cumplían diez años de su muerte en Montevideo. La imponente presencia de "el gran muerto", como lo llamaba Reyes, y la enorme admiración que éste le prodigaba, ${ }^{9}$ lo movieron a gestionar un homenaje al autor de La amada inmóvil en la orilla oriental: "Al acercarse el décimo aniversario del fallecimiento de Amado Nervo, juzgué conveniente procurar que los países del Plata hicieran algo en su recuerdo. Como conozco la calidez de los entusiasmos uruguayos y allá murió Nervo, me pareció que -aparte de lo que yo, personalmente y con mi pluma, hiciera en Buenos Aires- habría que intentar el acto público más bien en Montevideo" (Reyes 1993: 206). A pesar de tener esto claro, Reyes se vio en la encrucijada de a quién solicitarle el encargo, si a Luisi

8 El campo literario uruguayo manifestó el luto por el poeta mexicano a través de obituarios en periódicos y números de homenaje organizados en revistas. En la prensa del día se leen convocatorias al velatorio para los asociados al Círculo de Autores Uruguayos, el Círculo de Prensa, los gremios de maestros, profesores de secundaria y de la Universidad. En los meses siguientes, revistas como Ariel y Teseo dedicaron números especiales a la memoria del poeta. Juana de Ibarbourou y Emilio Frugoni publicaron colaboraciones en el volumen especial de la revista argentina Nosotros. Frugoni también publicó una nota en La razón (26 de mayo de 1919). Agradezco a Daniela Kaplan su apoyo con el rastreo y relevamiento hemerográfico.

9 Alfonso Reyes se encargó de preparar la edición de las Obras completas de Nervo, editadas por Biblioteca Nueva (Madrid, 1920), para lo que debió emprender la búsqueda de todos los textos escritos por el autor. Del estudio prolongado del poeta y su obra, surgió el ensayo de Reyes Tránsito de Amado Nervo, publicado en 1937. 
o a Ibarbourou, dada la cercanía que tenía con ambas y la admiración por Nervo que sentían las dos escritoras. Finalmente se inclinó por la última. ${ }^{10}$ Así, el 7 de mayo de 1929, le hacía a Juana "un encargo de piedad: el día 24 del mes de mayo en curso se cumplen los diez años del fallecimiento de Amado Nervo, quien murió, como Ud. sabe, en Montevideo, en el Parque Hotel. ${ }^{11}$ Amiga mía: Ud. que posee la voz más pura, convoque a algunos poetas escogidos: hagan un acto breve y claro en memoria de aquel justo" (Reyes e Ibarbourou 2001: 37). Ante este pedido, la poeta se comprometió a dar vida a dos eventos:

Lo que Ud. desea de Nervo se hará con verdadero placer. Me ocupo ya de organizar dos actos: una conferencia en el Centro Gallego, que es hoy por hoy uno de los salones más prestigiosos y lujosos de acá y "una hora de fervor en memoria de Nervo" en la Universidad. Además, pienso en un álbum que se pondría en el atrio de la Universidad para ser firmado por el pueblo y enviarlo luego a México, o un pergamino con un mensaje a Vd., firmado por los intelectuales uruguayos (2001: 39).

También le solicitó al escritor "un buen retrato de Nervo" (2001: 40) para exponerlo en el acto. Reyes cumplió con remitirle la imagen y además le envió a la autora una carta en la que comentaba datos de la infancia de Nervo con la indicación de que la publicara en Montevideo. Así se hizo y el

10 En la correspondencia reservada a Estrada, dejó un relato de cómo manejó la situación entre las dos escritoras: "La parte delicada de la tarea era el homenaje público que yo deseaba en Montevideo. En aquella ciudad, como Ud. sabe, Luisa Luisi organizó hace tiempo cierto Comité Uruguay-México que trabajó muy bien a los comienzos, y al que yo mismo debo los brillantes agasajos y cariñosas fiestas con que fui recibido allá por mayo del año pasado. [...] Por otra parte, me parecía más digno de la memoria de Nervo que fuera Juana de Ibarbourou la que organizara tal homenaje, y entre ambas mujeres se ha producido hace mucho no sé qué disidencia, que por lo demás saben cubrir y disimular con perfecta discreción. Opté por el camino directo y escribí a ambas; me encontré con que Luisa estaba sin elementos, y ella misma reconocía que la iniciativa le tocaba a Juana" (Reyes 1993: 207).

11 El Parque Hotel fue el alojamiento más prestigioso de Montevideo durante la primera parte del siglo xx. Ubicado frente al paseo marítimo y al parque urbano que lleva el nombre de Rodó, el hotel fue inaugurado en 1909. Desde sus primeros tiempos, fue centro importante de la vida social montevideana, con fiestas memorables en sus salones. Allí también se alojó Reyes en varias estadías en la capital uruguaya. 
texto vio la luz en el Imparcial del 19 de mayo de 1929 (Zaïtzeff 2001: 37). Con este gesto el escritor mexicano favorecía a Juana (la "autorizaba" a la organización del homenaje a Nervo) y dotaba de prestigio a la actividad que le había encargado. ${ }^{12}$

Con verdadera entrega, Ibarbourou se ocupó de movilizar a lo más destacado de la intelectualidad uruguaya, según se comprueba en las notas de prensa que cubren el evento y algunas cartas enviadas en procura del apoyo de ciertas figuras. Así, escribió a Emilio Oribe, su gran amigo y paisano, solicitándole que brindara un discurso en el acto que se celebraría en la Universidad. La carta entraña cierto interés en tanto deja entrever que la fama del poeta modernista convivía con el rechazo en ciertos sectores de la intelectualidad uruguaya, que condenaban la cursilería de su estilo. Juana lo defiende de esta suerte: "Nervo es un valor, digan lo que digan". ${ }^{13}$ Otro punto interesante de la misiva en cuestión es que en ella la autora consigna que no desea para el acto: "Nada de declamadoras, ni Comités, etc. [...] En el estrado, diplomáticos exclusivamente, para evitar invitaciones de compromiso y nombres de compromiso aún". ${ }^{14}$ Se hace patente, en este pasaje, la distancia que interpone la poeta entre su activi-

12 Juana formó parte de la pléyade de escritoras mujeres que publicaron poemas por la muerte de Nervo. Como éste, la autora profesaba el catolicismo y adhería a una concepción místico-religiosa de la labor poética, aspectos estos que podrían explicar la afinidad y la admiración manifestada por la escritora. Por otra parte, resulta pertinente agregar que la elección de una poeta mujer para el homenaje al autor de Nayarit, por parte de Reyes, no resulta accidental, pues la recepción del poeta modernista entre las lectoras mujeres había representado un verdadero fenómeno de seducción (véase Martínez 2015). De hecho, en la asistencia al encuentro con Nervo en el Ateneo de Montevideo el 16 de mayo de 1919, el público femenino fue dominante, según lo reseñó la prensa local: "El salón, repleto de distinguida concurrencia femenina en su mayoría, recibió con una salva de aplausos la entrada del ilustre poeta mejicano y su comitiva" (La Razón, 17 de mayo de 1919: 8).

13 Véase la carta inédita de Ibarbourou a Oribe, 1929, Archivo Literario de la Biblioteca Nacional de Uruguay.

14 Hemos accedido también a una carta de la poeta a Carlos Quijano, en la que le comunica información acerca del día, hora y el orden de oradores (Oribe, Delgado, el propio Quijano y Frugoni), seguramente a efectos de que la información fuera publicada en el diario El País, del cual Quijano era redactor responsable (carta del 22 de mayo de 1929, Colección Carlos Quijano, Archivo General de la Nación, Uruguay). 
dad y aquellas del Comité Uruguay-México, evidenciándose con claridad que desea deslindar el homenaje a Nervo de las actividades organizadas por Luisi y su grupo, para lo que cuenta con el aval de Reyes. ${ }^{15}$

Finalmente, se llevaron a cabo los dos actos planificados. Uno en el Centro Gallego, el 24 de mayo ${ }^{16}$ y el otro -y más importante- en la sede de la máxima casa de estudios de la nación, el 31 de mayo de 1929. Los dos homenajes fueron exitosos y representaron la última muestra del periodo delimitado como del "fervor mexicano" en Uruguay. Según el testimonio de Juana: "Jamás se ha visto tal cantidad de gente dentro y fuera de la Universidad. [...] Nervo sigue viviendo en Montevideo" (Reyes e Ibarbourou 2001: 42). Días después, la poeta le envió a Reyes recortes de los diarios en los que se daba noticia de los actos, "donde hay frases de justicia y admiración para Ud.".

Hay que agregar asimismo que Ibarbourou no sólo se ocupó de los detalles del homenaje en Montevideo, también tuvo una acción sumamente relevante en la recuperación de la obra inédita de Nervo, pues tomó contacto con la última novia del poeta, una dama argentina. Señala en una carta a Reyes: "La Sra. de Hill Hamilton vendrá a visitarme la próxima semana y me traerá los datos y una copia de los versos que el grande y querido poeta le dedicó" (Reyes e Ibarbourou 2001: 35). Tras hacerse con los textos, Ibarbourou se los envió a Reyes, quien los publicó más tarde como documentos inéditos en la edición de Poesías completas de Nervo, editado por Alfonso Méndez Plancarte. El ensayo de Reyes "El viaje de amor de Amado Nervo" se basa en estos hallazgos.

Por último, en el texto "A vuelta de correo" el escritor-diplomático dejó un duradero reconocimiento a la labor de Ibarbourou en la organiza-

15 Hay que apuntar que Reyes escribió asimismo a Luisa Luisi para que emprendiera gestiones en este sentido ante la revista Alfar, de la que era colaboradora. Luisi atendió al pedido del escritor y publicó una nota titulada "Un recuerdo de la muerte de Amado Nervo" (Luisi 1929), la que incluyó una dedicatoria a Alfonso Reyes.

16 En el Centro Gallego tuvo lugar una conferencia de Carlos Zum Felde (1881-1938) (carta inédita de Ibarbourou Oribe, 1929). Esta puntualización responde a que Serge Zaïzeff (2001: 42) indicó que debía tratarse del reconocido crítico Alberto Zum Felde, pero en realidad el orador fue su hermano Carlos, también escritor. 
ción de la "conmemoración inolvidable" de Montevideo, a la que "prestó toda su diligencia y todo el fuego de su alma" (Reyes 1958: 429). A través del homenaje a Nervo, Reyes legitimó a Ibarbourou y a sí mismo como herederos espirituales del autor más representativo del modernismo por entonces. En ese acto de donación de representatividad, habría que señalar también la conciencia de su papel como máxima figura de la cultura mexicana en el Río de la Plata en ese momento. De este modo Reyes atendió sus dos condiciones: la del diplomático que debía encargarse de la buena propaganda de México y el literato que debía velar por la fidelidad a una determinada tradición poética. A través del encargo del homenaje a Ibarbourou, el intelectual realizó una clara transferencia de prestigio que completaría meses después, en agosto de ese mismo año, cuando en un acto multitudinario en el Palacio Legislativo la poeta fuera desposada con América.

\section{MÉXICO EN LA CONSAGRACIÓN DE "JuANA DE AMÉRICA"}

Una fotografía ha ilustrado reiteradamente los capítulos dedicados a la vida y obra de Ibarbourou, aquella que la muestra escoltada por dos escritores de renombre en la ceremonia que marcaría su apoteosis como "Juana de América". ${ }^{17}$ Del hombre a su derecha, Juan Zorrilla de San Martín (1855-1931), el "poeta de la patria", se ha comentado el apoyo que brindó a la autora tanto en el ámbito personal como en el literario, fungiendo como padrino de boda del enlace religioso de la poeta con el capitán Lucas Ibarbourou en 1921 y como padrino de sus desposorios simbólicos con América en 1929 (Rocca 2011). A la izquierda de la escritora, figura un hombre cercano a los cuarenta años, un consagrado escritor extranjero, en funciones diplomáticas. Se trataba de Alfonso Reyes y representaba, en ese acto, a las letras continentales. Hasta el momento, no se ha profundizado en las implicancias de su presencia en la ceremonia y las condiciones del patrocinio intelectual brindado a la autora.

17 La idea del ungimiento de la poeta como "Juana de América" partió originalmente de José Santos Chocano, en 1924 (Puentes de Oyenard 1998: 30). 
El contexto del acto que tuvo lugar el 10 de agosto de 1929 es el de un país que se preparaba para los festejos del Centenario. La atmósfera era de optimismo y Juana de Ibarbourou representaba al Uruguay de excepción que había venido forjando el longevo batllismo. La autora no sólo encarnaba el modelo cívico de mujer-madre-esposa, sino también el vitalismo y la modernidad que deseaba promover el gobierno. Como ha planteado María Inés de Torres, la poesía de Juana era la expresión artística de la filosofía del Estado batllista y el hecho puntual de que la celebración se desarrollara en el recién inaugurado monumento del Palacio Legislativo "hizo que la ceremonia (y por lo tanto la figura de Juana) quedara innegable y obviamente asociada al poder público" (Torres 2013: 212).

Los entresijos de la preparación del acto son relevantes. En primer lugar, es menester apuntar que el mismo no fue organizado por el Estado uruguayo, sino por un conjunto de estudiantes e intelectuales organizados en un Comité de Homenaje. Entre los materiales que se conservan en el Archivo Alfonso Reyes es posible consultar una invitación formal al evento - enviada por el mencionado comité- y que justifica la presencia de Reyes en tanto "representa y encarna una de las más altas figuras mentales de la patria de Nervo", lo que reafirma la pertenencia a una tradición escritural de base modernista. También hay que mencionar otra misiva enviada al escritor, en julio de 1929, por el poeta y representante estudiantil José Pedro Héguy Velazco (1908-1962), quien había conocido a Reyes en ocasión del homenaje organizado por el Comité Uruguay-México, donde participó como orador. El texto reza como sigue: "Abocado dicho Comité al problema de quién sería la voz que del consorcio intelectual de América representaría la literatura del continente en la apoteosis de la insigne uruguaya, resolvió por aclamación solicitar fuera la voz suya la que se alzara en ese momento que marcaría una verdadera época en nuestra literatura por saberlo dueño de una recia y alta envergadura de poeta y escritor y gran amigo de esta tierra".

En el programa definido para el acto se incluían actuaciones musicales, oratoria y la colocación de un anillo a la poeta por parte de Juan Zorrilla de San Martín como símbolo de sus desposorios con América. 
Nos interesa especialmente detenernos en el discurso pronunciado por Reyes, titulado "Otra Juana de América". En este proponía un elogio de la poeta uruguaya a la que representa como un "faro": "Alguien aquí nos prestaba sus risas y sus gemidos; alguien aquí nos devolvía la confianza en las posibilidades del espíritu; alguien aquí oraba por nosotros" (Reyes [1929] 2001: 105). El reconocimiento del tenor espiritual de la poeta habla de la común sensibilidad - y afinidad - existente entre las dos figuras y es al mismo tiempo la raíz que los une a Nervo.

Pero lo más destacado del elogio de Reyes es la propuesta de una identificación entre Juana de Ibarbourou y la escritora novohispana Juana Inés de la Cruz. Resulta pertinente señalar que la figura de la poeta mexicana venía experimentando por entonces un rescate tras casi doscientos años de olvido a raíz de los prejuicios literarios e ideológicos de los neoclásicos primero y de los románticos después hacia la estética barroca; para ellos, los escritos de la monja poeta se presentaban como un producto corrompido y ampuloso, resultado de la decadencia del gongorismo. Amado Nervo (entre los primeros, con el ensayo Juana de Asbaje) Pedro Henríquez Ureña, los jóvenes poetas nucleados en torno a la revista Contemporáneos y Reyes fueron entusiastas y esforzados promotores de su obra, una recuperación que, según ha estudiado Stanton (2003), los distanciaba de la obstinación del arte nacionalista que llevaba adelante parte del sistema cultural posrevolucionario, pues estos intelectuales proponían, como contraparte, el logro de una literatura moderna de exigencia universal.

La presencia de Sor Juana en la consagración de Ibarbourou constituye un nuevo gesto de reconocimiento de Reyes hacia la uruguaya, puesto que la analogía que propone opera como un reconocimiento o validación de esta última como heredera de Sor Juana.

Notaréis que he dicho: "otra mujer". No tanto por evocar otras figuras de poetisas de hoy o de ayer que ya viven en nuestra mente [...] sino porque la asociación del nombre mismo me ha hecho pensar en la otra Juana de América, en la ardiente monja mexicana del siglo XviI: Sor Juana Inés de la Cruz. A la distancia de tierras y de siglos, he aquí dos voces diferentes (ave, aquélla, trabada en la jaula de oro del silogismo y del concepto, y no 
por eso menos canora: ave, ésta, prendida en la más frágil rama, sacudida en vano por el viento de la locura, y no por eso menos firme y menos acordada); he aquí dos voces que concuerdan en ofrecer los paraísos no vedados de la imaginación y de la esperanza como alivio contra la vida, y el tapiz volante de la palabra como un talismán verdadero para escapar a las mezquinas gravitaciones (Reyes [1929] 2001: 106).

A través de esta intervención, Reyes continuó colaborando en la consagración de Ibarbourou que había iniciado con el encargo del homenaje a Nervo. Al proponerla como heredera de la "Monja poeta" dotó a la uruguaya de un linaje (y no hay que olvidar el peso de éste y de la tradición en las operaciones de legitimación), le proporcionó una genealogía preclara y femenina, y al mismo tiempo le otorgó visibilidad a la cultura mexicana en uno de los hechos más recordados de la historia literaria de América Latina. Juana, por su parte, agradeció en su discurso el homenaje y subrayó la presencia protagónica de Reyes que "me ha traído la voz de su México de maravillas" (Ibarbourou 1953: 958-959).

Poco tiempo después, en 1930, la editorial española Cervantes publicaría una antología de poemas de Juana (una "edición homenaje", se consigna en la portada). En ella se lee como nota introductoria una reseña anónima del acto de coronación de "Juana de América" en el que llamativamente se pone de relieve el protagonismo de Alfonso Reyes en la ceremonia, a diferencia del relato más conocido que lo pone en paridad con Juan Zorrilla de San Martín: "El acto solemne fue presidido por Alfonso Reyes, y a él se asociaron con unánime sentimiento de admiración, las autoridades uruguayas, el cuerpo diplomático y representantes de la intelectualidad de todos los países hispanoamericanos" (Ibarbourou 1930: III). El énfasis en el protagonismo de Reyes en ese relato de los hechos es significativo en tanto podría servir para argumentar el peso del capital simbólico del autor y de México en el proceso de consagración de la poeta en el extranjero. ${ }^{18}$

En su Diario, el propio autor señalaba su protagonismo en la ceremonia: "Llegué con Manuela a bordo del General Artigas, invitado a presidir esta tarde en el Palacio Legislativo el homenaje del Uruguay a Juana de Ibarbourou" (Reyes 2010: 146). 
Si bien los contactos entre Reyes e Ibarbourou comenzaron a espaciarse en el transcurso de los años, los "favores" o estrategias de promoción entre ambos no se redujeron a los eventos estudiados. ${ }^{19}$ Así, con motivo de una - de las cinco- candidaturas al Nobel de Alfonso Reyes, la que liderara Gabriela Mistral en 1949, la escritora uruguaya escribió una nota laudatoria en la que consignaba su "devoción" por el regiomontano y la importancia que tuvo para ella su amistad: "Es una de mis grandes riquezas de mujer sin fortuna. Porque ser amiga de Alfonso Reyes es una envidiable y bien envidiada opulencia" (Reyes e Ibarbourou 2001: 108). El remate al repaso de las virtudes intelectuales y personales del escritor fue la expresión de su "anhelo de que por él nuestra América vuelva a recibir los laureles mundiales del premio Nobel de Literatura" (Reyes e Ibarbourou 2001: 109). En 1959, el favor se invertiría, tocándole esta vez a Reyes corresponder en el apoyo de la candidatura de Ibarbourou al Nobel. El comité que la promovía solicitó su adhesión así como la gestión de un apoyo institucional ante la Universidad Nacional de México y la Academia Mexicana de la Lengua. La adhesión de Reyes fue inmediata, según reza un cable: "ya propuse personalmente la candidatura nuestra Juana" (86), si bien el autor admite que habrá un obstáculo para la obtención de avales en su país puesto que también había sido presentada la candidatura de José Vasconcelos. Al tener noticia de esto, la propia Juana escribiría a Reyes agradeciéndole el apoyo e insistiendo en la necesidad de que el autor la ayudase en la conquista de los beneplácitos internacionales que podrían asegurarle el premio: "Todo lo que poseíamos se nos fue hundiendo, sin esperanza, en el tembladeral. iY ahora, Santo bendito, Ud. que es la victoria de América, toma en sus manos augustas, el destino de ese premio que puede salvarnos! iAlfonso, Alfonso, Alfonso!" (Reyes e Ibarbourou 2001: 87-88).

19 La mirada de Reyes sobre Juana cambia con el tiempo, distanciándose de la representación idealizada de su primera estancia en el Río de la Plata. El 17 de febrero de 1937, registra una visita a Montevideo y "a Juanita de Ibarbourou, rechoncha ya como palomita pichona, y ya francamente extravagante de cara, burguesita y artificial a pesar de todo, en su casa, siempre en arreglos" (Reyes 2012: 87). 
Como es sabido, ninguno de los dos escritores recibió el galardón de la Academia Sueca. No obstante, sus intercambios en torno a los homenajes, ceremonias y premios resultan ilustrativos de cómo "las relaciones personales prevalecen en los universos de producción simbólica, que están muy poco reglamentados y, a su vez, fundados en el carisma" (Sapiro 2016: 44).

\section{CONCLUSIONES}

La profundización en el estudio de los intercambios entre Reyes e Ibarbourou a finales de la década de 1920 desarrollada en este trabajo ha procurado echar luces sobre las formas en las que la relación personal de dos escritores reconocidos y con fuertes vínculos con el poder (el intelectual consagrado en América y Europa y embajador de México en Argentina, que era Reyes, y la poeta-emblema de la modernidad de la nación uruguaya que era Juana de Ibarbourou) ayudó no sólo a mantener o mejorar sus posiciones, sino también a consagrar obras, tradiciones e imágenes de la literatura y la cultura nacionales. Atendiendo a esto, hemos repasado cómo Reyes mostró gran versatilidad al combinar la labor oficial (con las dificultades que ésta le presentaba) con su propia agenda como intelectual, lo que también aplica para el caso de Ibarbourou, quien a través de las estrategias de la debilidad y su colaboración con el autor, se vio beneficiada por el capital social del mismo.

Pero más allá de esta muestra de las implicancias políticas de las afinidades y preferencias literarias que surcaron la amistad entre Reyes e Ibarbourou, este trabajo ha querido aproximarse al vínculo de los autores con el capital simbólico e imagología que sus respectivos países procuraban proyectar por entonces (y que habilitaría una reflexión más amplia sobre el servicio del intelectual latinoamericano a los proyectos del Estado). De este modo, la participación de Reyes como representante de alcance continental en el ungimiento de "Juana de América" colaboró con la propaganda del Uruguay del Centenario, una república triunfante en reformas y 
libertades, que elegía a una mujer letrada como cara visible de la nación. Por otra parte, Ibarbourou prestó - a su modo y a través de la alianza con Reyes - un servicio al México posrevolucionario, en tanto asoció su figura a determinadas imágenes de aquel país, las que respondían a una dimensión más "espiritual", humanista y universalista que las promovidas por otros sectores.

No está de más insistir en que, en este México que recortan o seleccionan los autores, destaca el peso del modernismo como canal de encuentro no sólo en el desarrollo de un entramado decisivo para la conformación de las redes de los años veinte, sino también en relación a la comunión de sensibilidades (identidades o pertenencias estético-ideológicas) forjadas a la luz de las obras modernistas, como lo confirma la "hora de fervor" montevideana dedicada a Amado Nervo. Es atendiendo a la afinidad con la misma tradición humanista y espiritualista que también se podría justificar la presencia de Sor Juana — dada su recuperación por parte de los escritores mexicanos de tendencia universalista— en la consagración de la poeta uruguaya.

Por último, sólo nos resta señalar que el estudio del caso de estos escritores en 1929 debería proyectarse y comprenderse sobre un marco más amplio: el de la revitalización del americanismo durante el periodo de entreguerras, pues fue sin duda el reposicionamiento continental en relación con Europa el que trajo aparejado un cambio en las relaciones entre las naciones latinoamericanas (como la referida aproximación Uruguay-México) y el fortalecimiento de redes intelectuales que dieran sustento (en términos de producción, difusión y recepción) a una expresión y un campo cultural propiamente americanos. 
BIBLIOGRAFÍA

Amado Nervo: crónica y discursos con motivo de los funerales del poeta nayarita en 1919. José Sarukhán (pról.). México: UNAM-Dirección General de Fomento Editorial: Asociación Nayarita de Egresados de la UNAM, 1995.

BLIXEN, CARINA. "De poetisa a poeta: la aventura intelectual". Alicante: Biblioteca Virtual Miguel de Cervantes, 2014. Texto disponible en línea en http://www.cervantesvirtual.com/nd/ark:/59851/bmczs4r3 (consultado el 14 de febrero de 2019).

BOURDIEU, PIERRE. Las reglas del arte: génesis y estructura del campo literario. Thomas Kauf (trad.). Barcelona: Anagrama, 1995.

Castañón, Adolfo. "Introducción". Alfonso Reyes. Diario II. París, 19 de marzo de 1927- Buenos Aires, 4 de abril de 1930. Adolfo Castañón (ed.). México: Academia Mexicana de la Lengua. El Colegio de México/El Colegio Nacional/FCE/INBA/Capilla Alfonsina/UAM/UANL/UnAM, 2010. Xv-xxxv.

"El Comité Uruguay-México hace conocer su programa de acción". El País, Montevideo, 10 de mayo 1928, 3.

Frugoni, Emilio. La lección de Méjico. Montevideo: Imprenta Augusta, 1928.

Garciadiego, Javier. "Alfonso Reyes en la Argentina: desencuentros diplomáticos y amistades literarias". Autores, editoriales, instituciones y libros. Estudios de historia intelectual. México: El Colegio de México, 2015. 229-254.

Gros Espiell, HÉCTOR. "Amado Nervo en Montevideo". Revista de la Universidad de México 471 (1990): $42-47$.

IANES, RAÚL. "Leer sobre el hombro: correspondencias y terrores de lecturas compartidas". Monographic Review XXVI, Hysteria, Hallucination and Madness in Hispanic Literature (2010): 210-233.

IBARBOUROU, JuANA DE. Edición homenaje (las mejores poesías). Barcelona: Editorial Cervantes, 1930. 
"Discurso pronunciado el 10 de agosto de 1929". Obras completas. Dora Isella Russell (comp.). Madrid: Aguilar, 1953. 957-959.

Ludmer, Josefina. "Tretas del débil". Patricia Elena González y Eliana Ortega (eds.). La sartén por el mango. Encuentro de escritoras latinoamericanas. Puerto Rico: El Huracán, 1984. 47-54.

LuISI, LuISA. "Discurso de homenaje a Alfonso Reyes". La pluma 7 (1928):19-21.

_. "Un recuerdo de la muerte de Amado Nervo". Alfar 63 (1929): 16-17.

MarTíneZ, José MaríA. Amado Nervo y las lectoras del Modernismo. Madrid: Verbum, 2015.

Moraes Medina, Mariana. "Crónica de una efusión: Alfonso Reyes, Luisa Luisi y el Comité Uruguay-México". Revista de Historia de América 156 (2019): 217-239.

Novo, Salvador. "Continente vacío", en Viajes y ensayos I. Sergio González Rodríguez (comp.). México: FCE, 1996.

PUENTES DE OYENARD, SYLVIA. "Apuntes para una biobibliografía de Juana de Ibarbourou". Juana Ibarbourou. Obras escogidas. Santiago de Chile: Andrés Bello, 1998.

RAMA, CARLOS. "La Revolución mexicana en Uruguay". Historia Mexicana 2 (1957): 161-186.

REYES, ALFONSO. "Otra Juana de América" (1929). Grito de auxilio. Correspondencia. Serge I. Zaïtzeff (comp.). México: El Colegio Nacional, 2001. 105-106.

"Compás poético". Sur 1 (1931): 64-73.

"Carta a Juana de Ibarbourou" [1929], Tránsito de Amado

Nervo. Obras completas. VIII, México: FCE, 1958. 427-449.

"A vuelta de correo", Obras completas. VIII. México: FCE, 1958.

Y GENARO ESTRADA. Con leal franqueza. Correspondencia entre Alfonso Reyes y Genaro Estrada. Tomo II. Compilación y notas de Serge I. Zaïzeff. México: El Colegio Nacional, 1993.

y JuANa De Ibarbourou. Grito de auxilio. Correspondencia. Serge I. Zaitzeff (comp.), México, El Colegio Nacional, 2001. 
Misión diplomática. Tomo II. Víctor Díaz Arciniega. México: FCE /Secretaría de Relaciones Exteriores, 2001.

Diario II. París, 19 de marzo de 1927-Buenos Aires, 4 de abril de 1930. Adolfo Castañón (ed.). México: Academia Mexicana de la Lengua/El Colegio de México/El Colegio Nacional/FCE/INBA/Capilla Alfonsina/UAM/UANL/UNAM, 2010.

Diario IV. Buenos Aires, 1 de julio de 1936 - México, 8 de febrero de 1939. Alberto Enríquez Perea (ed.). México: FCE/AML/COLMEX/El Colegio Nacional/ INBA/CA/UAM/UANL/UnAM, 2012.

ROCCA, PABLO. Juana de. Ibarbourou: las palabras y el poder. Montevideo: Yaugurú, 2011.

SAPIRO, GISÈLE. La sociología de la literatura. Buenos Aires: FCE, 2016.

Stanton, Anthony. "Sor Juana entre los Contemporáneos". Crítica sin fin: José Gorostiza y sus críticos. Álvaro Ruiz Abreu (ed.). México: Conaculta, 2003. 279-307.

TORRES, INÉS DE. "Una poeta para América: hipótesis de lectura sobre la obra de Juana de Ibarbourou en la década de 1920". Cuadernos de literatura 34 (2013): 202-216.

"Juana de América: la Ibarbourou en sus memorias". Políticas de la Memoria 17 (2017): 51-58.

VASCONCElos, José. La raza cósmica. Notas de viaje. Notas de viajes a la América del Sur. Barcelona: Agencia Mundial de Librería, 1925.

YANKELEVICH, PABLO. Miradas australes: propaganda, cabildeo y proyección de la Revolución mexicana en el Río de la Plata, 1910-1930. México: Instituto Nacional de Estudios Históricos de la Revolución Mexicana, 1997.

ZÄ̈TZEFF, Serge. Grito de auxilio. Correspondencia. Serge I. Zaïtzeff (comp.). México: El Colegio Nacional, 2001. 
ARCHIVOS CONSULTADOS

Archivo Particular de Alfonso Reyes. Capilla Alfonsina/INBAL/Secretaría de Cultura, México. Expediente núm. 1498, Luisa Luisi.

Archivo Particular de Alfonso Reyes. Capilla Alfonsina/INBAL/ Secretaría de Cultura, México. Expediente núm. 1243, Juana de Ibarbourou.

Archivo Literario de la Biblioteca Nacional de Uruguay. Colección Juana de Ibarbourou.

Archivo General de la Nación, Uruguay. Colección Carlos Quijano. 